\title{
Experimental Study on Impermeability Law of Aquiclude Reconstructed by Mudstone of External Dump in Arid Zone
}

\author{
Li Ma $\mathbb{D}^{1,},{ }^{1,2}$ Chendong Liu $\mathbb{D}^{1,2}$ Yinli Bi, ${ }^{3}$ Suping Peng, ${ }^{4}$ Kaisheng Jiang, ${ }^{5}$ Hui Zhang, \\ Qiang Luo $\mathbb{C}^{1,},{ }^{1,2}$ Fei Xue, ${ }^{1,2}$ Tianxin $\mathrm{Xu},{ }^{1,2}$ Tianxiang $\mathrm{Li},{ }^{1,2}$ Jing $\mathrm{Wu},{ }^{1}$ Jiahao Tian, ${ }^{1}$ \\ and Dongxu Zhang ${ }^{7}$ \\ ${ }^{1}$ School of Energy Engineering, Xi'an University of Science and Technology, Xi'an, Shaanxi 710054, China \\ ${ }^{2}$ Institute of Surface Mining Technology, Xi'an University of Science and Technology, Xi'an, Shaanxi 710054, China \\ ${ }^{3}$ College of Geology and Environment, Xi'an University of Science and Technology, Xi'an 710054, China \\ ${ }^{4}$ State Key Laboratory for Coal Resources and Safe Mining, China University of Mining \& Technology (Beijing), Beijing 100083, \\ China \\ ${ }^{5}$ Shenhua Xinjiang Qitai Energy Co., Ltd., Changji 831799, Xinjiang, China \\ ${ }^{6}$ International Exchange and Cooperation Office, Xi'an University of Science and Technology, Xi'an 710054, Shaanxi, China \\ ${ }^{7}$ CCTEG Shenyang Research Institute, Fushun 113122, Liaoning, China
}

Correspondence should be addressed to Chendong Liu; lcd6552@yeah.net

Received 6 January 2021; Accepted 6 May 2021; Published 18 May 2021

Academic Editor: Xueping Fan

Copyright (c) $2021 \mathrm{Li} \mathrm{Ma}$ et al. This is an open access article distributed under the Creative Commons Attribution License, which permits unrestricted use, distribution, and reproduction in any medium, provided the original work is properly cited.

In order to achieve the goal of ecological restoration, plant irrigation, and water retention in the external dump of open-pit coal mine in the arid desert area, it is proposed to use the mudstone in the stripped material to reconstruct the surface aquiclude and improve the water holding capacity of the topsoil. By taking the Hongshaquan Open-Pit Coal Mine as the study object, the red mudstone of mining level +650 was selected as the topsoil aquiclude material through the geological survey. XRD diffraction experiments are used to determine the composition of red mudstone including kaolinite mineral, quartz, potash feldspar, albite, and illite. The moisture content of the red mudstone is $4.16 \%$ as measured by the indoor drying experiment. And the particle size of $0.5 \mathrm{~mm}, 1 \mathrm{~mm}$, and $2 \mathrm{~mm}$ and the thickness of $5 \mathrm{~cm}, 10 \mathrm{~cm}$, and $20 \mathrm{~cm}$ rock samples were selected to conduct the indoor soil column experiment. Three indicators of initial infiltration rate, stable infiltration rate, and average infiltration rate were obtained according to the analysis and calculation of the water column drop rate, wet peak drop rate, and cumulative infiltration rate so that the permeability law and coefficient of each group of tests can be known. The finite element transient analysis theory and numerical simulation method were adopted to verify the results of physical experiments. The research results show that +650 level red mudstone has a strong antiseepage ability, and the smaller the particle size, the better the antiseepage performance. For $0.5 \mathrm{~mm}$ and $2 \mathrm{~mm}$ particle sizes, as the paving height increases, the water-proof effect is better. The laying height of $1 \mathrm{~mm}$ particle size has no obvious influence on the water barrier effect. The physical simulation was confirmed to have the same result trend as the numerical simulation, both of which are quadratic functions with the error within a reasonable range.

\section{Introduction}

In the process of open-pit coal mining, a large amount of topsoil and stone is removed and an empty site is needed for disposal, which damages the original terrain of the mining area and leads to the deterioration of soil and regional ecological environment. Therefore, it is of great significance to carry out mine land reclamation and ecological restoration in the process of mining and after mine closure [1] (Ma et al. 2017). Especially for the arid desert areas, as it has 
the characteristics of less rainfall and large evaporation, combined with the impact of open-pit mining on the terrain structure, the topsoil structure of the dump site has a loose structure, strong permeability, poor water retention capacity, and large irrigation water requirements. Hence, it is necessary to study the permeability law and parameters of water barrier reconstruction for maintaining the ecological restoration, irrigation cycle, and water consumption in the open-pit mine of the arid area.

Under natural conditions, the soil profile in the stratum has a layered structure, which can maintain certain infiltration characteristics and rate. The external dump material of open-pit mine is made of loose material such as rock, mudstone, and sandstone, which has large porosity and strong water permeability between materials. In addition, due to the low rainfall and large evaporation in the mining area, there is no groundwater in the lower part of the reconstructed external dump. Only a small part of the water is absorbed by plants, most of the irrigation water is lost along the vertical direction of the external dump, and it has poor water function to maintain plant growth, which is easy to cause water loss in topsoil prematurely, seriously affecting plant growth or increasing irrigation water consumption.

According to the structural characteristics and principle of the vadose zone, the water barrier is reconstructed inside the external dump to reduce or prevent the vertical infiltration of atmospheric precipitation and irrigation water. In line with the phreatic impact layer, a stagnant water layer is formed on the upper part of the water barrier. The water layer allows the water blocked by the water barrier layer to rise along the soil pores through capillary action, as a result, capillary water supply from stagnant water layer to plant root. The structure is shown in Figure 1.

There are several studies related to the reconstruction of the aquifer at home and abroad. Some scholars obtained the variation curve of permeability coefficient with time through variable head experiment and carried out a feasibility analysis for the error [2-6] (Ma et al., 2020; Wang, 2019; Zhao et al., 2018; Li et al., 2016; and Cao et al., 2010). Based on the experiment of bentonite and nonbentonite, Chen et al. (2010) and Bojana (2009) concluded that there is an obvious relationship between water conductivity and soil properties $[7,8]$. By studying the permeability change of the coal seam under the action of plastic flow, Guo et al. $(2019,2020)$ obtained the relationship between the permeability and the relative residual strain and the influence coefficient of the confining pressure $[9,10]$. Burger et al. (2001), Niu et al. (2009), Robert et al. (2004), and Aubertin et al. (2003) obtained equations that are more suitable for experiments by modifying and optimizing theoretical equations [11-14]; Zhu et al. (2014), Zhang et al. (2013), and Robert et al. (2001) discussed the experimental methods of different soil permeability coefficients, determined the error range through comparative experiments, and summarized the error sources to determine the appropriate functional relationship [15-17].

In order to provide a theoretical foundation for realizing ecological restoration of external dump and topsoil water conservation in the open-pit mine of arid areas, the red mudstone of mine level +650 from the Hongshaquan open- pit coal was taken as the research object. The physical soil column experiments and numerical simulation were adapted to explore the permeability coefficient and permeability law of the red mudstone.

\section{Project Overview of Hongshaquan Open-Pit Coal Mine}

2.1. The Environment of Mine Area. Hongshaquan Open-Pit Coal Mine is located in the southeast of Junggar Basin. It belongs to the temperate continental climate, and the annual average temperature is $5.5^{\circ} \mathrm{C}$. The annual average precipitation is $269.4 \mathrm{~mm}$, and summer generally accounts for $40-50 \%$ of the total annual precipitation; spring and autumn are nearly equivalent, each accounting for $20-30 \%$, the winter precipitation is the least, accounting for less than $10 \%$ of the annual precipitation. The evaporation capacity is $2141 \mathrm{~mm}$, the annual average wind period is about $100 \mathrm{~d}$, and the wind speed is generally $3 \sim 4 \mathrm{~m} / \mathrm{s}$. Low rainfall, large evaporation, and frequent winds resulting from the surface water storage around the stope and dump are scarce, while the irrigation water demand is large. Figure 2 shows the exterior view of the external dump site of the Hongshaquan Open-Pit Coal Mine.

2.2. Selection of Mudstone Antiseepage Materials. As the open-pit mine is located on the northern edge of the eastern part of the Junggar Basin, the exposed strata such as $\mathrm{Pa}$ leozoic Carboniferous and Permian, Mesozoic Triassic and Jurassic, Neogene of Cainozoic and the fourth series, and the Paleozoic strata constituting the base of the Mesozoic strata were included.

By geological surveys, it is found that the rock of mining level +650 on the east side of the stope has good physical and chemical properties of mudstone (Figure 3 ). The mudstone belongs to the Shishugou Group of the Middle-Upper Mesozoic Jurassic System $\left(\mathrm{J}_{2-3} \mathrm{sh}\right)$. Its lithology is variegated fluke-lacustrine facies. The upper subgroup mainly consists of red argillaceous siltstone, mudstone intercalated with sandstone. The lower subgroup mainly consists of green argillaceous siltstone, mudstone, and silicified wood. And the storage is abundant, with a thickness of $116 \mathrm{~m}-900 \mathrm{~m}$.

In order to furtherly confirm the mineral composition content of mudstone, XD-3X-ray diffractometer was used to perform XRD diffraction experiments on the rock samples. First grinding the granular solid into powder with a mortar, then pouring the clean powder sample into the center of a clean sample pan, covering with a clean iron sheet to make the surface of the sample flat, and finally entering the test parameters with the scanning angle from 0 to $90^{\circ}$, scanning speed of $4^{\circ} / \mathrm{min}$, working voltage of $36 \mathrm{kV}$, and electric current of $20 \mathrm{~A}$, the XRD experimental map shown in Figure 4 is obtained.

It can be seen from Figure 4 that the peak intensity of the curve has obvious peaks (4) and (5) when the $2 \theta$ is $27.5^{\circ}$ and $29^{\circ}$. The diffraction peaks (1), (6), and (7) are illite, (2) and (3) are quartz, and the diffraction peaks (4) and (5) are the 


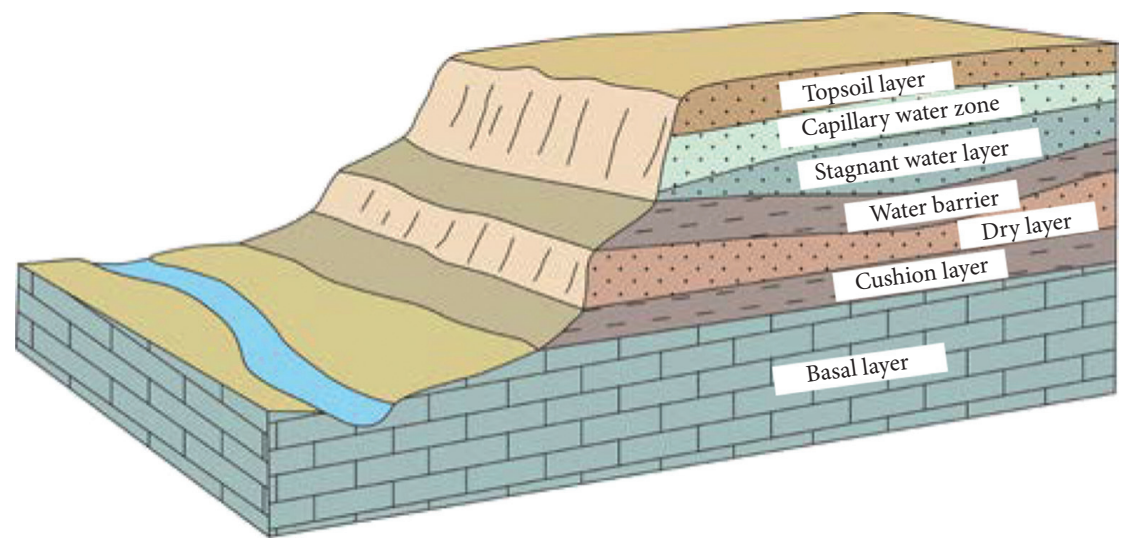

Figure 1: Schematic diagram of aquiclude reconstruction of the external dump.

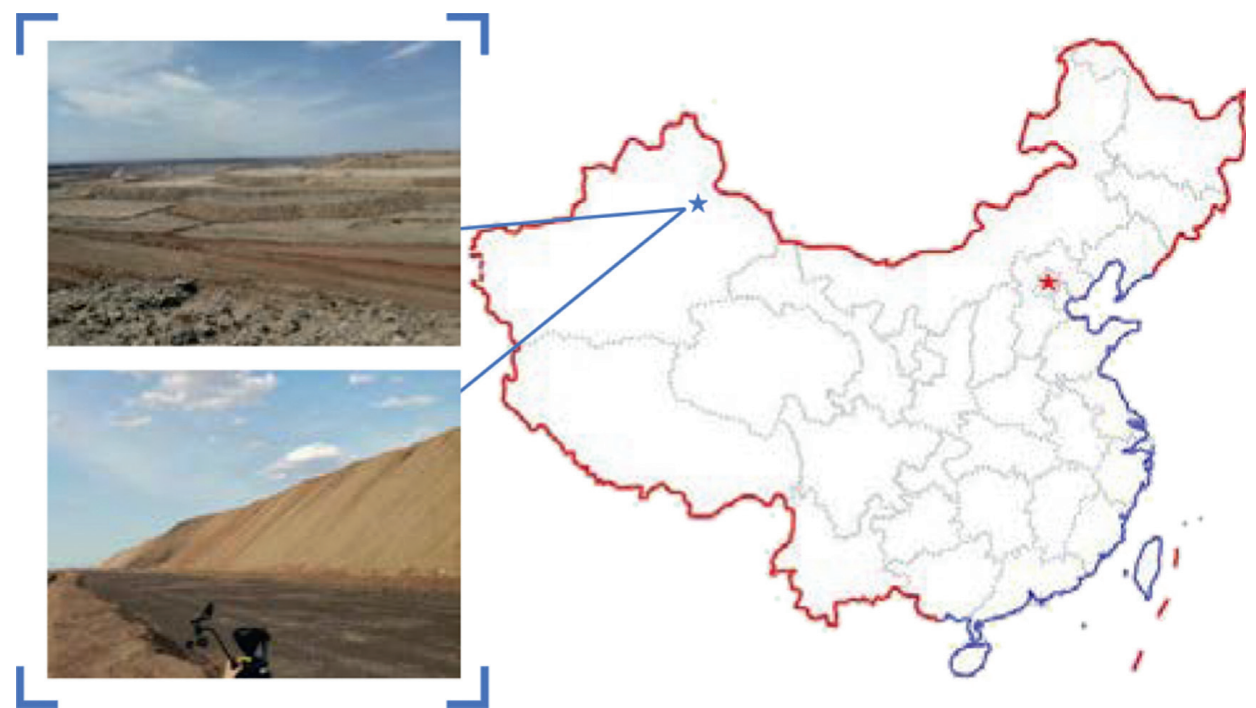

Figure 2: The location and external dump site of Hongshaquan open-pit mine.

diffraction peaks of potassium feldspar and albite, respectively. Due to the presence of potash feldspar and albite in mudstone, the mudstone is reddish-brown.

Considering that there may be other impurities in the rock sample which may interfere with the results of the XRD diffraction experiment, the known identified minerals are reconfirmed. The rock samples were calcined at different high temperatures, and the XRD diffraction experiment was continued. The treatment temperature was $300^{\circ} \mathrm{C}, 500^{\circ} \mathrm{C}$, and $800^{\circ} \mathrm{C}$, and the calcination time was 30 minutes. The comparison chart is shown in Figure 5.

The comparison of the experimental results shows that the diffraction peaks (5) and (6) of the rock sample have a tendency to weaken after the high temperature calcination treatment at $800^{\circ} \mathrm{C}$; especially the diffraction peak (6) weakens more significantly, and it is indicated that potash feldspar and albite will gradually disappear after high temperature treatment. The diffraction peak (2) has no change in the peak after high temperature treatment; it is indicated that the crystal plane distance remains unchanged after high temperature treatment. This peak indicates that the mineral is illite. Thus, the final mineral composition is kaolinite mineral, quartz, potash feldspar, albite, and illite.

\section{Soil Column Experiment on Seepage Control Law of Mudstone in Water Isolation Layer}

\subsection{Experiment Preparation}

3.1.1. Seepage Test Materials. To explore the permeation law of different material parameters, particle size and thickness are key influence factors to be considered. By crushing and sieving repeatedly, the experimental materials were sorted into 9 groups of soil columns with three different particle sizes of $0.5 \mathrm{~mm}, 1 \mathrm{~mm}$, and $2 \mathrm{~mm}$ and different heights of $5 \mathrm{~cm}, 10 \mathrm{~cm}$, and $20 \mathrm{~cm}$ [18]. The experimental material packing density parameters are shown in Table 1 . After the drying experiment, the initial soil moisture content was $4.16 \%$. 


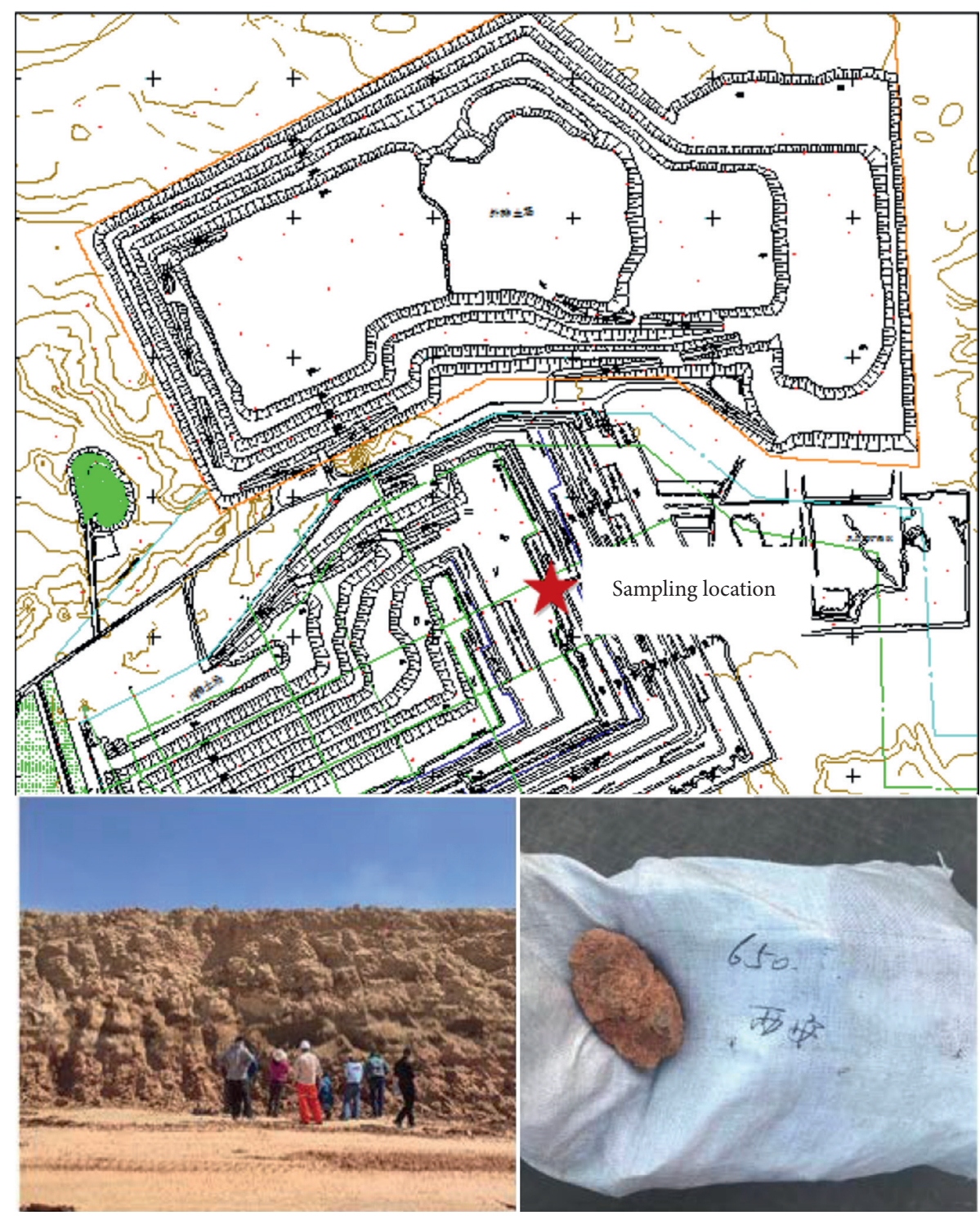

FIgURE 3: On-site rock sample collection.

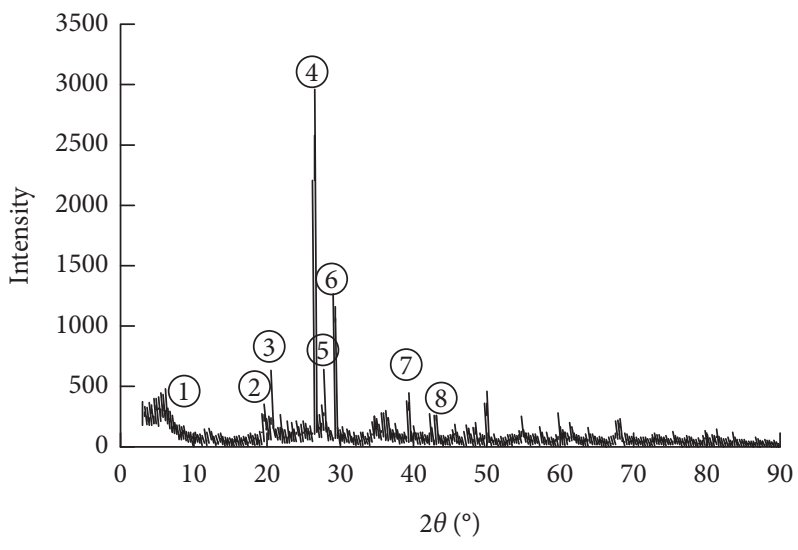

FIgURE 4: The experimental map of XRD. 


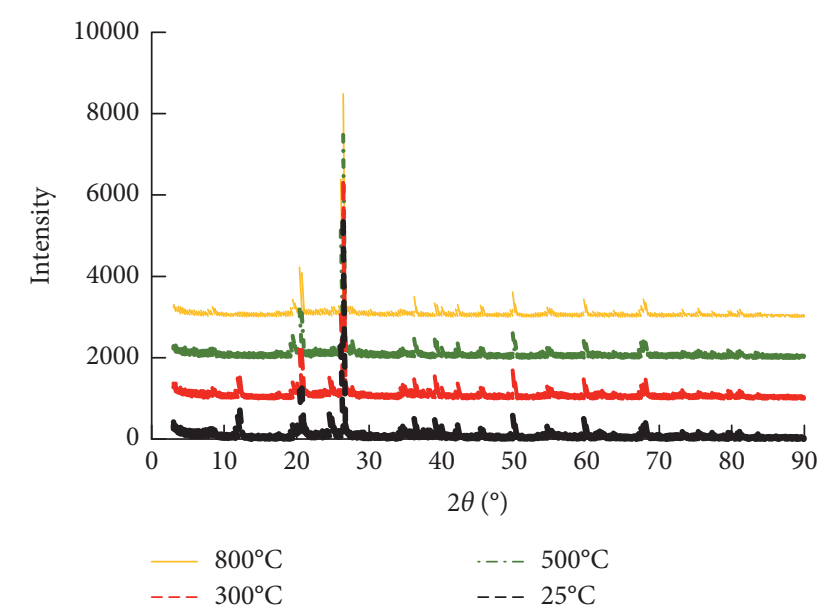

FIGURE 5: Comparison of XRD diffraction experiments at different temperatures.

TABLe 1: Experimental material density.

\begin{tabular}{lccc}
\hline Size $(\mathrm{mm})$ & \multicolumn{3}{c}{ Height $(\mathrm{cm})$} \\
\hline 0.5 & 5 & 10 & 20 \\
1 & $1360 \mathrm{~kg} / \mathrm{m}^{3}$ & $1400 \mathrm{~kg} / \mathrm{m}^{3}$ & $1327 \mathrm{~kg} / \mathrm{m}^{3}$ \\
2 & $1093 \mathrm{~kg} / \mathrm{m}^{3}$ & $1067 \mathrm{~kg} / \mathrm{m}^{3}$ & $1047 \mathrm{~kg} / \mathrm{m}^{3}$ \\
\hline
\end{tabular}

3.1.2. Equipment Required for Soil Column Experiment. The experiment requires a plexiglass tube with an inner diameter of $14 \mathrm{~cm}$ and height of $50 \mathrm{~cm}$; 3L beaker; 200 mesh geo-sieve of $0.25 \mathrm{~mm}, 0.5 \mathrm{~mm}, 1 \mathrm{~mm}, 2 \mathrm{~mm}$, and $5 \mathrm{~mm}$; crusher; geo-hammer; material basket; tamping pestle; filter paper; gauze; red and blue ink; scale bars; and so forth.

\subsection{Experimental Principle of Soil Column Based on Variable} Head Method. The infiltration performance of soil water can be described by soil physical characteristic parameters. In this paper, through the analysis and calculation of the water column drop rate, wet peak drop rate, and cumulative infiltration rate, three indicators of initial infiltration rate, stable infiltration rate, and average infiltration rate are obtained. Among them are the following:

(1) The initial infiltration rate:

The initial infiltration rate refers to the ratio of the drop height of the liquid level to the time within the first 6 hours:

$$
v_{0}=\frac{h_{1}}{6},
$$

where $v_{0}$ is the initial infiltration rate, $\mathrm{cm} / \mathrm{h}$, and $h_{1}$ is the height change corresponding to the first 6 hours, $\mathrm{cm}$.

(2) The stable infiltration rate:

The stable infiltration rate refers to the ratio of the drop height of the wet peak to the time during the stable water penetration period.

$$
v_{1}=\frac{h_{3}-h_{2}}{t_{3}-t_{2}}
$$

where $v_{1}$ is the stable infiltration rate, $\mathrm{cm} / \mathrm{h} ; h_{2}$ and $h_{3}$ are the height at the beginning and ending of stable infiltration, $\mathrm{cm} ; t_{2}$ and $t_{3}$ are the time of stable infiltration and the time to end the stable infiltration, $h$.

(3) The average infiltration rate:

The average infiltration rate is the ratio of the cumulative infiltration amount to the time used from the beginning of the test to the end of the test:

$$
v_{2}=\frac{h_{z}}{t_{z}},
$$

where $v_{2}$ is the average infiltration rate, $\mathrm{cm} / \mathrm{h} ; h_{\mathrm{z}}$ is the total height, $\mathrm{cm}$; and $t_{\mathrm{z}}$ is the total time of infiltration, $h$.

3.3. Seepage Experiment Method. The constant head method of the indoor permeability test is suitable for sandy soil and noncohesive soil with a small amount of gravel, and the variable head method is suitable for silt and cohesive soil [19]. The experiment was carried out in a closed laboratory without natural light, so the effect of evaporation was not considered. As the mudstone used has a strong antiseepage ability, the variable head method should be adopted for the permeability test with one-time adding water for simulating field irrigation. After the water level is stabilized, the infiltration rate of different particle sizes and heights can be calculated to determine the antiseepage effect by observing the height change of the water column, the distance of the wet peak migration, and the cumulative infiltration volume.

The sieved particles are added to a plexiglass column with an inner diameter of $14 \mathrm{~cm}$ and a height of $50 \mathrm{~cm}$ for filling. The bottom of the soil column needs to be added with gauze to prevent mudstone from clogging the mesh. Filter paper is added above the mudstone to relieve the impact of water during the water addition process. The experimental principle and device are shown in Figure 6. Measure the change of the wet peak, water column level, and water depth of the beaker which is also the cumulative infiltration volume. After the experiment, the results are processed. The corresponding curves of the wet peak, liquid level, and water depth of the beaker with time are shown in Figure 7.

The water depth of the test beaker can be converted into the cumulative infiltration amount in line with the size of the beaker. According to Figures 7(c) and 7(f), it can be seen that the $0.5 \mathrm{~mm} / 20 \mathrm{~cm}$ and $1 \mathrm{~mm} / 20 \mathrm{~cm}$ schemes never seeped or seeped rarely during the experiment, showing that the antiseepage effect of the two experimental schemes is excellent, and the cumulative infiltration amount has nothing to do with time. For the other 7 groups of experimental results obtained in Figure 7, the cumulative infiltration volume and time curve under different particle sizes and heights are summarized as shown in Figure 8. The horizontal axis of the fitting curve in this paper is the time, the vertical 


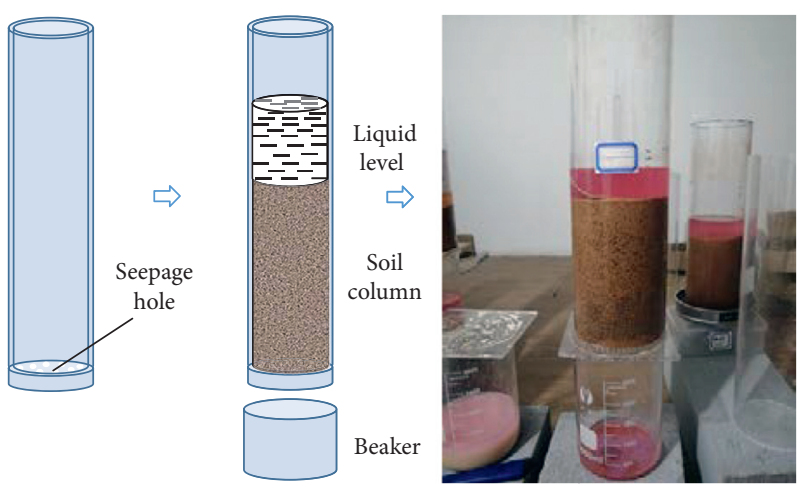

Figure 6: Experimental principle and device diagram.

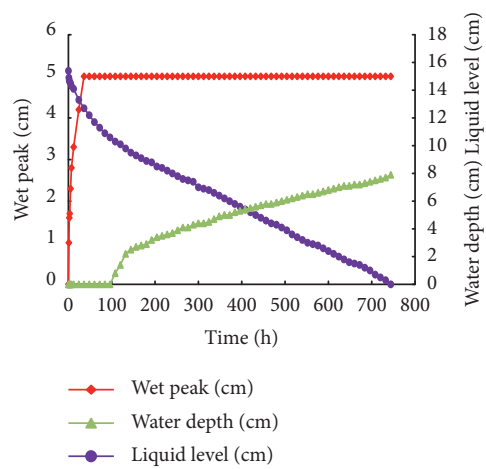

(a)
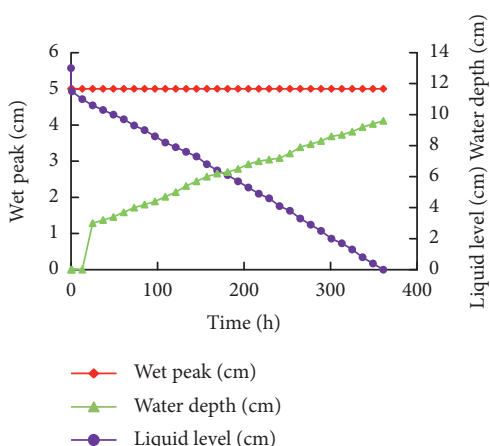

(d)

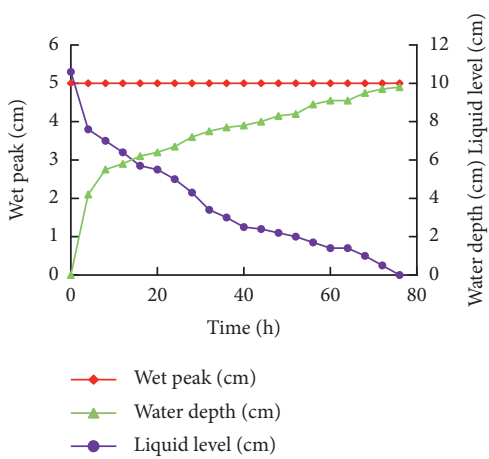

(g)

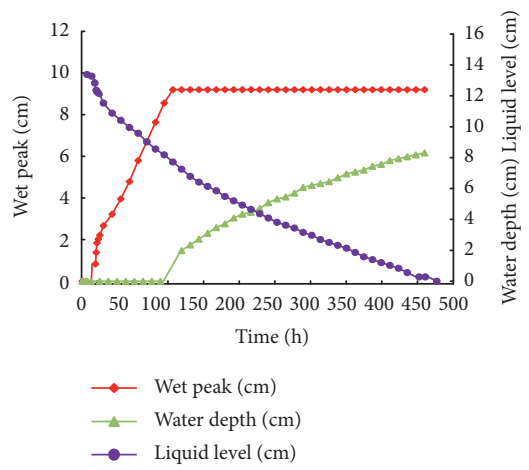

(b)

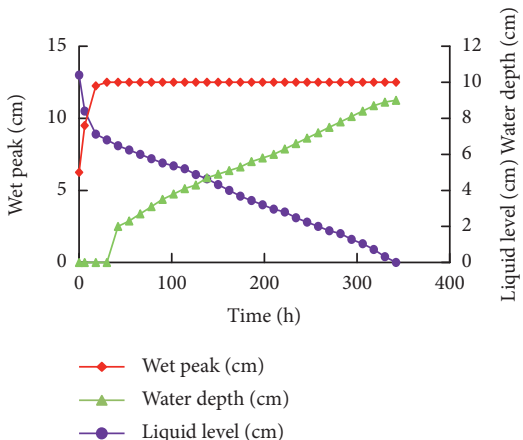

(e)

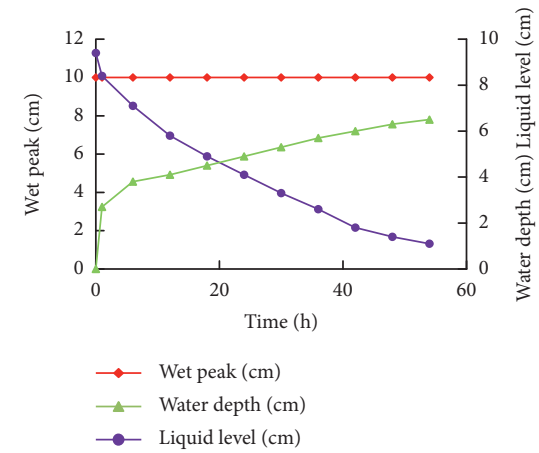

(h)

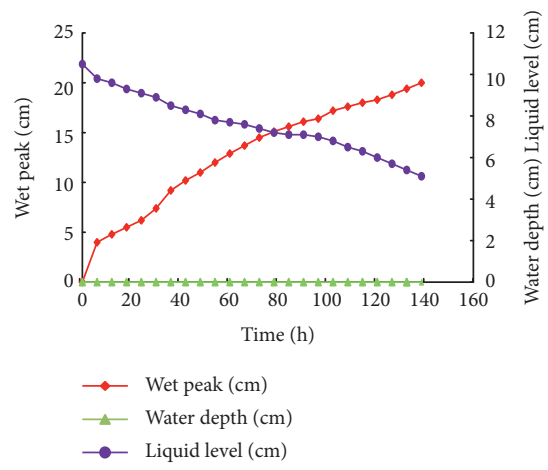

(c)

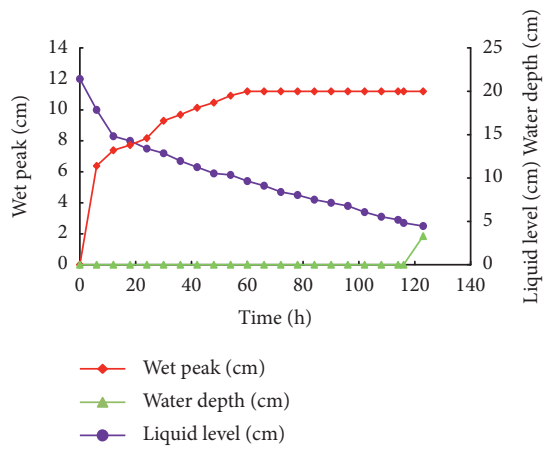

(f)

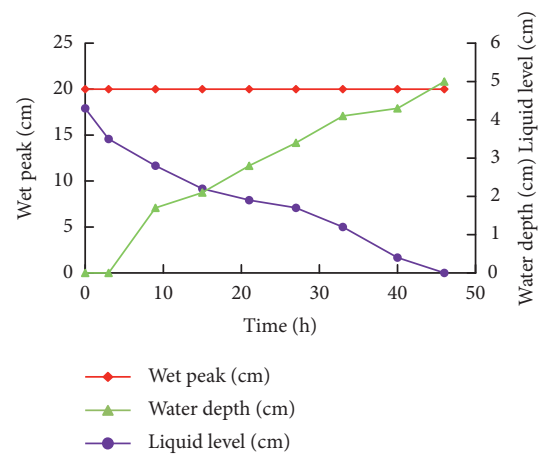

(i)

Figure 7: Curve of the relationship between wetting front, liquid level, water depth of beaker, and time: (a) $0.5 \mathrm{~mm} / 5 \mathrm{~cm}$ seepage curve of soil column experiment. (b) $0.5 \mathrm{~mm} / 10 \mathrm{~cm}$ seepage curve of soil column experiment. (c) $0.5 \mathrm{~mm} / 20 \mathrm{~cm}$ seepage curve of soil column experiment. (d) $1 \mathrm{~mm} / 5 \mathrm{~cm}$ seepage curve of soil column experiment. (e) $1 \mathrm{~mm} / 10 \mathrm{~cm}$ seepage curve of soil column experiment. (f) $1 \mathrm{~mm} / 20 \mathrm{~cm}$ seepage curve of soil column experiment. (g) $2 \mathrm{~mm} / 5 \mathrm{~cm}$ seepage curve of soil column experiment. (h) $2 \mathrm{~mm} / 10 \mathrm{~cm}$ seepage curve of soil column experiment. (i) $2 \mathrm{~mm} / 20 \mathrm{~cm}$ seepage curve of soil column experiment. 


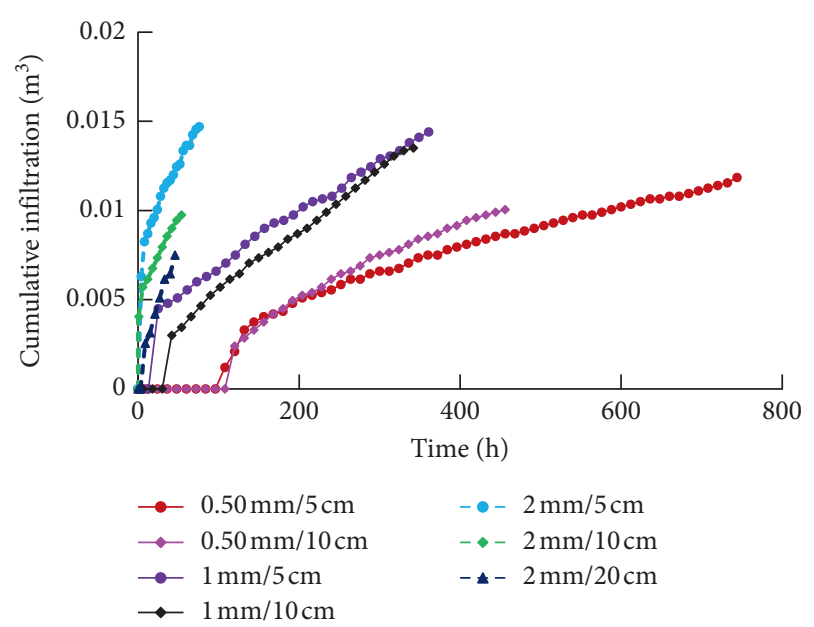

FIGURE 8: Relationship curve between cumulative infiltration volume and infiltration time.

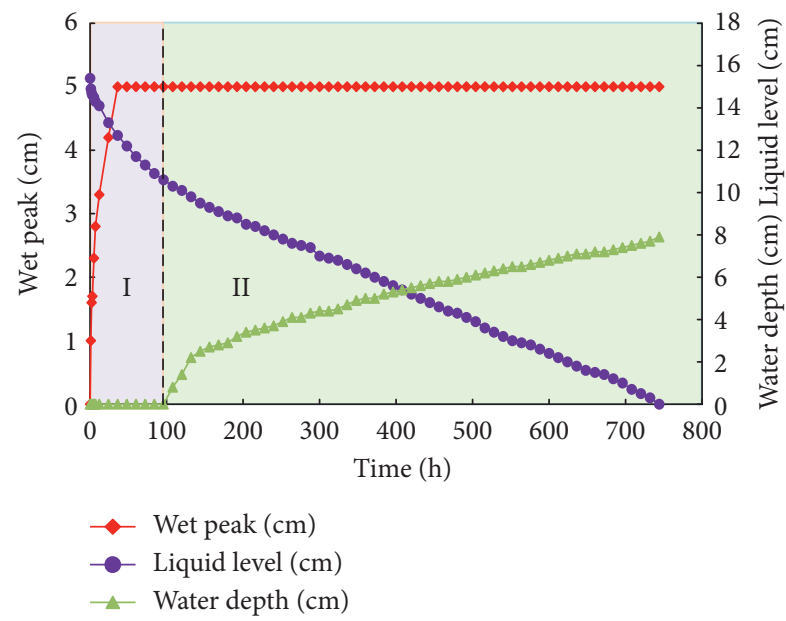

Figure 9: Demonstration of seepage experiment stage.

axis is the cumulative infiltration volume, and its slope is the infiltration rate.

Since mudstone has strong disintegration, the seepage process can be divided into two stages shown in Figure 9. The first stage is the stage of water absorption, expansion, and disintegration of mudstone. It takes various times for mudstones of different particle sizes and thicknesses to disintegrate. The second stage is after the completely disintegrated mudstone reaches a saturated state; it begins to enter the infiltration stage. Therefore, the permeability coefficient at the initial stage is unstable. Due to the characteristic relationship of the permeability, the initial disintegration stage of the experimental results of Figure 8 is pretreated as shown in Figure 10.

As shown in Figure 10, the relationship between the cumulative infiltration volume and time meets the growth trend of the quadratic function curve, and the growth rate is from fast to slow, and then tends to be linear. The fitting function can be listed in Table 2 .

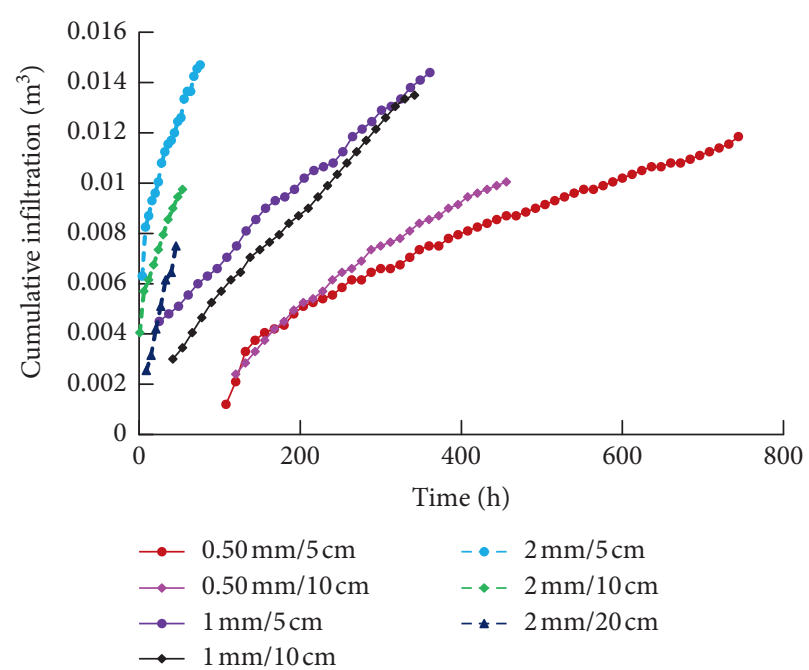

Figure 10: The relationship curve between cumulative infiltration volume and infiltration time after treatment.

3.4. Physical Experiment Data Processing. According to formulas (1)-(3), the initial infiltration rate, stable infiltration rate, and average infiltration rate were calculated by combining the wet peak height, liquid level height, and cumulative infiltration volume of each group of experiments. The results are shown in Table 3 .

The average infiltration rate corresponding to each particle size and height is fitted to form a three-dimensional surface diagram shown in Figure 11. The relationship among the average infiltration rate, the particle size, and height is obtained:

$$
\left\{\begin{array}{l}
f(x, y)=p_{00}+p_{10} x+p_{01} y, \\
p_{00}=-0.03056 \in(-0.0519,0.009214), \\
p_{10}=0.07762 \in(0.06552,0.08972), \\
p_{01}=-0.0006667 \in(-0.001877,0.0005433),
\end{array}\right.
$$

where $f(x, y)$ is the average infiltration rate of permeability coefficient, $x$ is the particle size of mudstone, in $\mathrm{mm}$; and $y$ is the height of laying mudstone, in $\mathrm{cm}$.

It can be seen from Figure 11 that the average infiltration rate of rock samples gradually increases with the increase of mudstone particle size and gradually decreases with the increase of paving thickness. The higher the average infiltration rate, the stronger the permeability, and the worse the antiseepage effect. That is, the smaller the mudstone particle size and the thicker the soil layer, the better the antiseepage effect.

\section{Numerical Simulation Method of Mudstone Permeability}

4.1. Principles of Transient Analysis. In the physical experiment of mudstone permeable soil column, water is added once, and related variables are measured at certain time intervals. It is the basic point to define the initial total head 


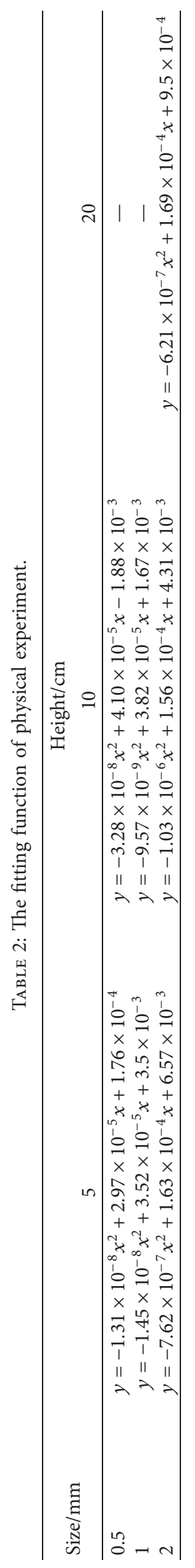


TABLE 3: Summary of experimental data processing results.

\begin{tabular}{|c|c|c|c|c|c|}
\hline \multirow{2}{*}{ Size $(\mathrm{mm})$} & \multirow{2}{*}{ Height $(\mathrm{cm})$} & \multirow{2}{*}{ Type } & \multicolumn{3}{|c|}{ Infiltration rate $\mathrm{cm} / \mathrm{h}$} \\
\hline & & & Initial & Stable & Average \\
\hline \multirow{9}{*}{0.5} & \multirow{3}{*}{5} & Wet peak & 0.43 & 0.07 & 0.14 \\
\hline & & Liquid level & 0.17 & 0.02 & 0.02 \\
\hline & & Cumulative & 0 & 0.01 & 0.01 \\
\hline & \multirow{3}{*}{10} & Wet peak & 0.38 & 0.08 & 0.09 \\
\hline & & Liquid level & 0.12 & 0.02 & 0.03 \\
\hline & & Cumulative & 0 & 0.02 & 0.01 \\
\hline & \multirow{3}{*}{20} & Wet peak & 0.67 & 0.11 & 0.14 \\
\hline & & Liquid level & 0.12 & 0.04 & 0.04 \\
\hline & & Cumulative & 0 & 0 & 0 \\
\hline \multirow{9}{*}{1} & \multirow{3}{*}{5} & Wet peak & - & - & - \\
\hline & & Liquid level & 0.28 & 0.03 & 0.04 \\
\hline & & Cumulative & 0 & 0.02 & 0.03 \\
\hline & \multirow{3}{*}{10} & Wet peak & - & - & - \\
\hline & & Liquid level & 0.42 & 0.03 & 0.04 \\
\hline & & Cumulative & 0 & 0.02 & 0.03 \\
\hline & \multirow{3}{*}{20} & Wet peak & 1.9 & 0.11 & 0.33 \\
\hline & & Liquid level & 0.33 & 0.05 & 0.08 \\
\hline & & Cumulative & 0 & 2.12 & 0.03 \\
\hline \multirow{9}{*}{2} & \multirow{3}{*}{5} & Wet peak & - & - & - \\
\hline & & Liquid level & 0.55 & 0.08 & 0.14 \\
\hline & & Cumulative & 0.8 & 0.06 & 0.13 \\
\hline & \multirow{3}{*}{10} & Wet peak & - & - & - \\
\hline & & Liquid level & 0.38 & 0.13 & 0.15 \\
\hline & & Cumulative & 0.63 & 0.06 & 0.12 \\
\hline & \multirow{3}{*}{20} & Wet peak & - & - & - \\
\hline & & Liquid level & 0.2 & 0.06 & 0.09 \\
\hline & & Cumulative & 0.17 & 0.11 & 0.11 \\
\hline
\end{tabular}

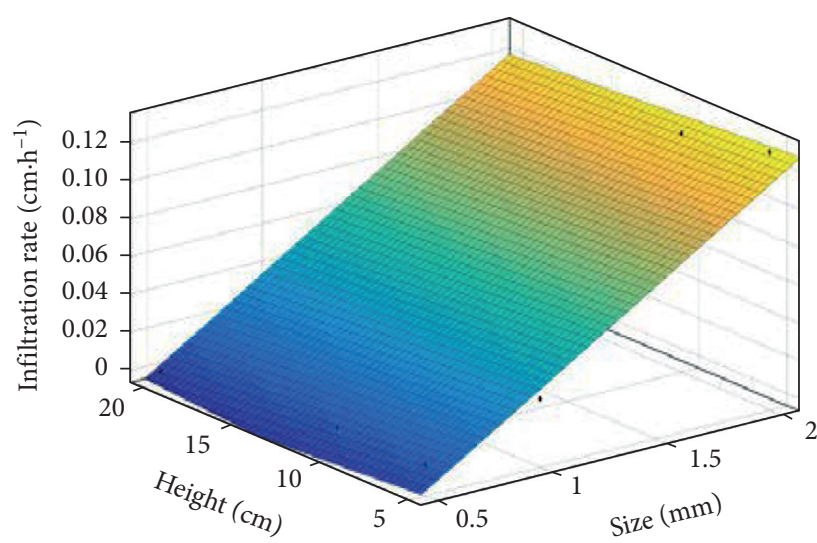

FIGURE 11: The average infiltration rate varies with the height of the particle size.

on all nodes. The two-dimensional seepage control differential equation using the transient analysis method can be expressed as

$$
\frac{\partial}{\partial x}\left(k_{x} \frac{\partial H}{\partial x}\right)+\frac{\partial}{\partial y}\left(k_{y} \frac{\partial H}{\partial y}\right)+Q=\frac{\partial \theta}{\partial t},
$$

where $H$ is the total head; $K_{x}$ is the permeability coefficient in the $x$ direction; $K_{y}$ is the permeability coefficient in the $y$ direction; $Q$ is the imposed boundary flow; $\theta$ is the water content per unit volume; and $t$ is the time.
The change of volumetric water content depends on the change of stress state and the properties of soil. Both saturated and unsaturated stress states can be expressed by two state quantities $\sigma-u_{a}$ and $u_{a}-u_{w}$ [20-22], where $\sigma$ is the total stress, $u_{a}$ is the atmospheric pressure in the pore, and $u_{w}$ is the pore water pressure.

It is assumed that, for transient problems, the atmospheric pressure of the pore is kept at constant atmospheric pressure; that is, $\left(\sigma-u_{a}\right)$ remains unchanged $[23,24]$ and has no effect on the change of water content per unit volume. Therefore, the change of water content per unit volume only depends on $\left(u_{a}-u_{w}\right)$. When $u_{a}$ remains unchanged, the water content per unit volume is only a function of water pressure. The relationship between water content per unit volume and pore water pressure is

$$
\partial \theta=m_{w} \partial u_{w}
$$

where $m_{w}$ is the slope of the water storage curve.

The total head $H$ is defined as

$$
H=\frac{u_{w}}{\gamma_{w}}+y
$$

where $u_{w}$ is the pore water pressure; $\gamma_{w}$ is the bulk density of water; and $y$ is the elevation.

Substituting formulas (6) and (7) into formula (5), we can get 


$$
\frac{\partial}{\partial x}\left(k_{x} \frac{\partial H}{\partial x}\right)+\frac{\partial}{\partial y}\left(k_{y} \frac{\partial H}{\partial y}\right)+Q=m_{w} \gamma_{w} \frac{\partial(H-y)}{\partial t} .
$$

Since the elevation is a constant, the derivative of $y$ with respect to time is 0 , and finally, the governing equation used in the finite element formula is [25-27]

$$
\frac{\partial}{\partial x}\left(k_{x} \frac{\partial H}{\partial x}\right)+\frac{\partial}{\partial y}\left(k_{y} \frac{\partial H}{\partial y}\right)+Q=m_{w} \gamma_{w} \frac{\partial H}{\partial t} .
$$

The Galerkin method with weighted margin is applied to the governing equation, and the finite element format of the two-dimensional seepage equation can be obtained:

$$
\begin{aligned}
& \tau \int_{A}\left([B]^{T}[C][B]\right) \mathrm{d} A\{H\}+\tau \int A\left(\lambda<N>^{T}<N>\right) \mathrm{d} A\{H\}, \\
& t=q \tau \int{ }_{L}\left(<N>^{T}\right) \mathrm{d} L,
\end{aligned}
$$

where $[B]$ is the gradient matrix; $[C]$ is the element permeability coefficient matrix; $\{H\}$ is the nodal head vector; $\langle N\rangle$ is the interpolation function vector; $q$ is the unit flow across the element boundary; $\tau$ is the element thickness; $t$ is the time; $\lambda$ is the storage item, which is equal to $m_{w} \gamma_{w}$ for transient seepage; $A$ is the sum sign on the unit area; $L$ is the sum sign on the unit boundary length.

In the case of axisymmetric, the complete hoop distance is $2 \pi R$. Since it is derived for 1 radian, the equivalent thickness is $R$. Therefore, the finite element equation in the case of axisymmetric is [28-30]

$$
\begin{aligned}
& \int_{A}\left([B]^{T}[C][B]\right) \mathrm{d} A\{H\}+\int A\left(\lambda<N>^{T}<N>\right) \mathrm{d} A\{H\}, \\
& t=q \tau \int_{L}\left(<N>^{T}\right) \mathrm{d} L .
\end{aligned}
$$

In the two-dimensional analysis, the thickness $\tau$ is different, the radial distance $R$ in an element is not a constant, and $R$ is variable in the integrand, so the finite element seepage equation can be simplified as

$$
[K]\{H\}+[M]\{H\}, t=\{Q\},
$$

where $[K]$ is the unit characteristic matrix; $[M]$ is the unit mass matrix; and $\{Q\}$ is the flow vector imposed on the unit.

The finite element solution of transient analysis is a function of time, and the time integration can be completed by the finite element difference approximation method. The finite element equation is written according to the finite difference to obtain the following equation:

$$
\begin{aligned}
(\omega \Delta t[K]+[M])\left\{H_{1}\right\}= & \Delta t\left((1-\omega)\left\{Q_{0}\right\}+\omega\left\{Q_{1}\right\}\right. \\
& +([M]-(1-\omega) \Delta t[K])\left\{H_{0}\right\},
\end{aligned}
$$

where $t$ is the time increment; $\omega$ is a coefficient between 0 and $1 ; H_{1}$ is the water head at the end of the time increment;
$H_{0}$ is the water head at the beginning of the time increment; $Q_{1}$ is the node flow at the end of the time increment; and $Q_{0}$ is the node flow at the beginning of the time increment.

4.2. Mudstone Seepage Law Based on Numerical Simulation. Firstly, by selecting the transient analysis, the duration was set as the experimental time, and the appropriate number of steps and soil parameters was set in the meantime. And the different model heights of $5 \mathrm{~mm}, 10 \mathrm{~mm}$, and $20 \mathrm{~mm}$ for the same particle sizes were established with the ratio of $1: 10$. Then, according to the experimental results of the soil column, the permeability coefficient $k_{\mathrm{T}}$ of each group of schemes can be calculated by $[3,7]$

$$
k_{T}=\delta \frac{\mathrm{aL}}{A\left(t_{2}-t_{1}\right)} \log \frac{H_{1}}{H_{2}},
$$

where $a$ is the cross-sectional area of the variable head tube, $\mathrm{cm}^{2} ; A$ is the sample area, $\mathrm{cm}^{2} ; \delta$ is the conversion factor of $\ln$ and $\log , \delta=2.3 ; L$ is the height of permeation diameter of the sample, $\mathrm{cm} ; t_{1}$ and $t_{2}$ are the start and end time of the measured water head, $h ; H_{1}$ and $H_{2}$ are the start and end of water head height, $\mathrm{cm}$.

According to the physical experiment data, the corresponding heights of mudstones with different particle sizes and different heights can be obtained by formula (14); they are shown in Table 4.

Secondly, the boundary conditions were set for the model. The head boundary function was adapted at the top of the model, the boundary conditions of zero total flow for the two sides, and the boundary conditions of zero pressure head for the bottom, as well as a flow monitoring line at the bottom. By Taking $0.5 \mathrm{~mm}$ particle size as an example, the total head stress cloud diagram at different soil layer thicknesses is shown in Figure 12. The permeability decreases approximately linearly in line with the thickness of the clay layer increases. According to the simulation calculation of different higher transient water levels, a transient head-time-seepage flow relationship table is listed in Table 5. As the transient head drops, seepage flow increases with the accumulation of time. The change rate of seepage flow presents a phenomenon of starting at a slow speed, and then from fast to slow, finally tending to be stable.

Based on the data obtained from the numerical simulation results, a scatter plot of each program can be drawn as Figure 13. The curve of time and cumulative infiltration volume obtained by numerical simulation has the same trend as the results of the soil column physical simulation (Figure 10), and both are quadratic: the initial growth rate is fast and then tends to be linear. Similarly, the fitting function that can obtain the numerical simulation results is shown in Table 6.

It can be seen that the simulation results of $0.5 \mathrm{~mm}$ and $1 \mathrm{~mm}$ rock samples have the same trend as the experimental results, and the error is kept within the error range. 
TABLE 4: The corresponding $k$ value of each group of experiments.

\begin{tabular}{lccc}
\hline Size $/ \mathrm{mm}$ & & Height $/ \mathrm{cm}$ & \\
& 5 & 10 & 20 \\
\hline 0.5 & 0.0105 & 0.015 & 0.014 \\
1 & 0.015 & 0.021 & 0.029 \\
2 & 0.044 & 0.081 & 0.154 \\
\hline
\end{tabular}
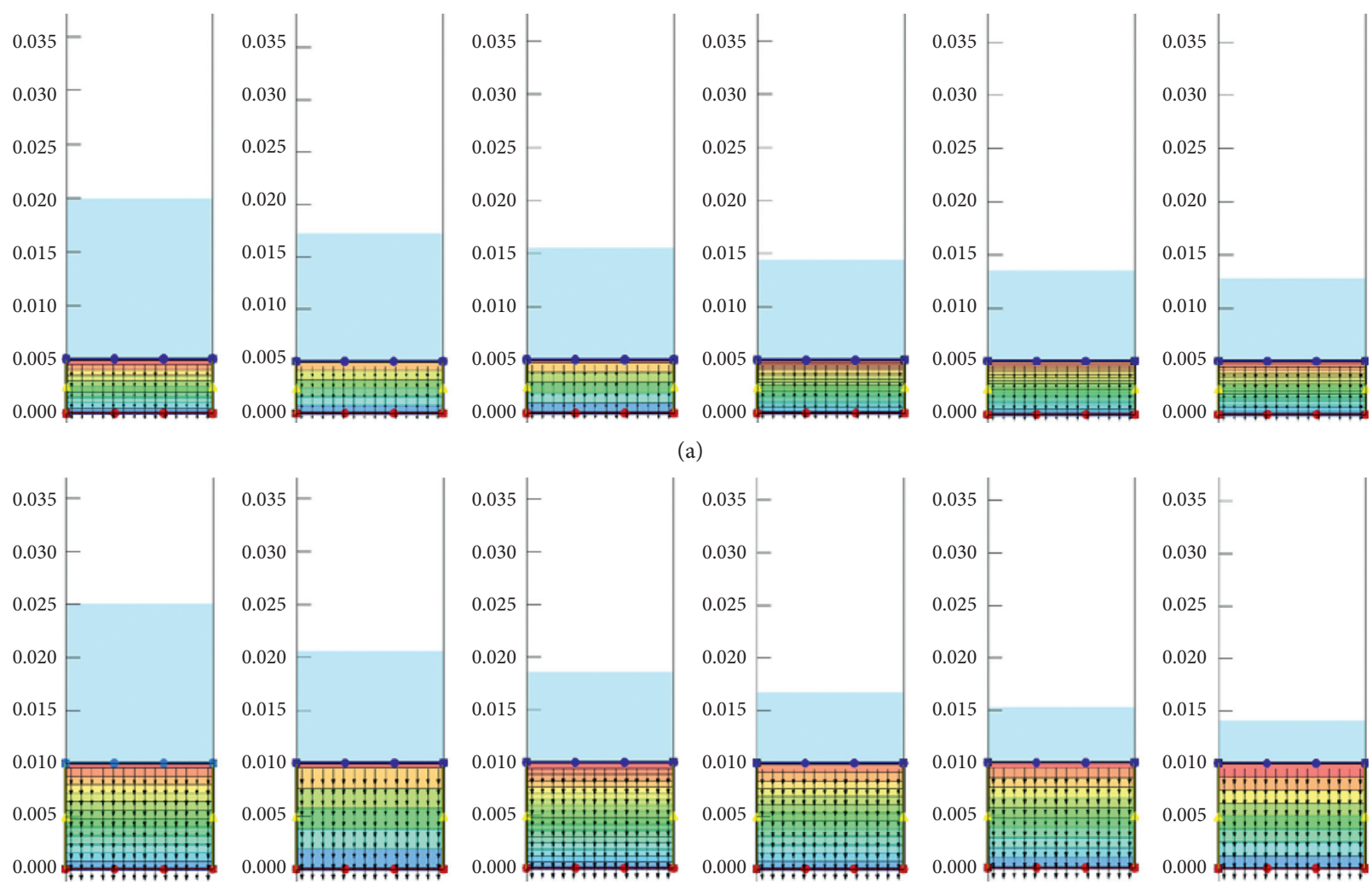

(a)
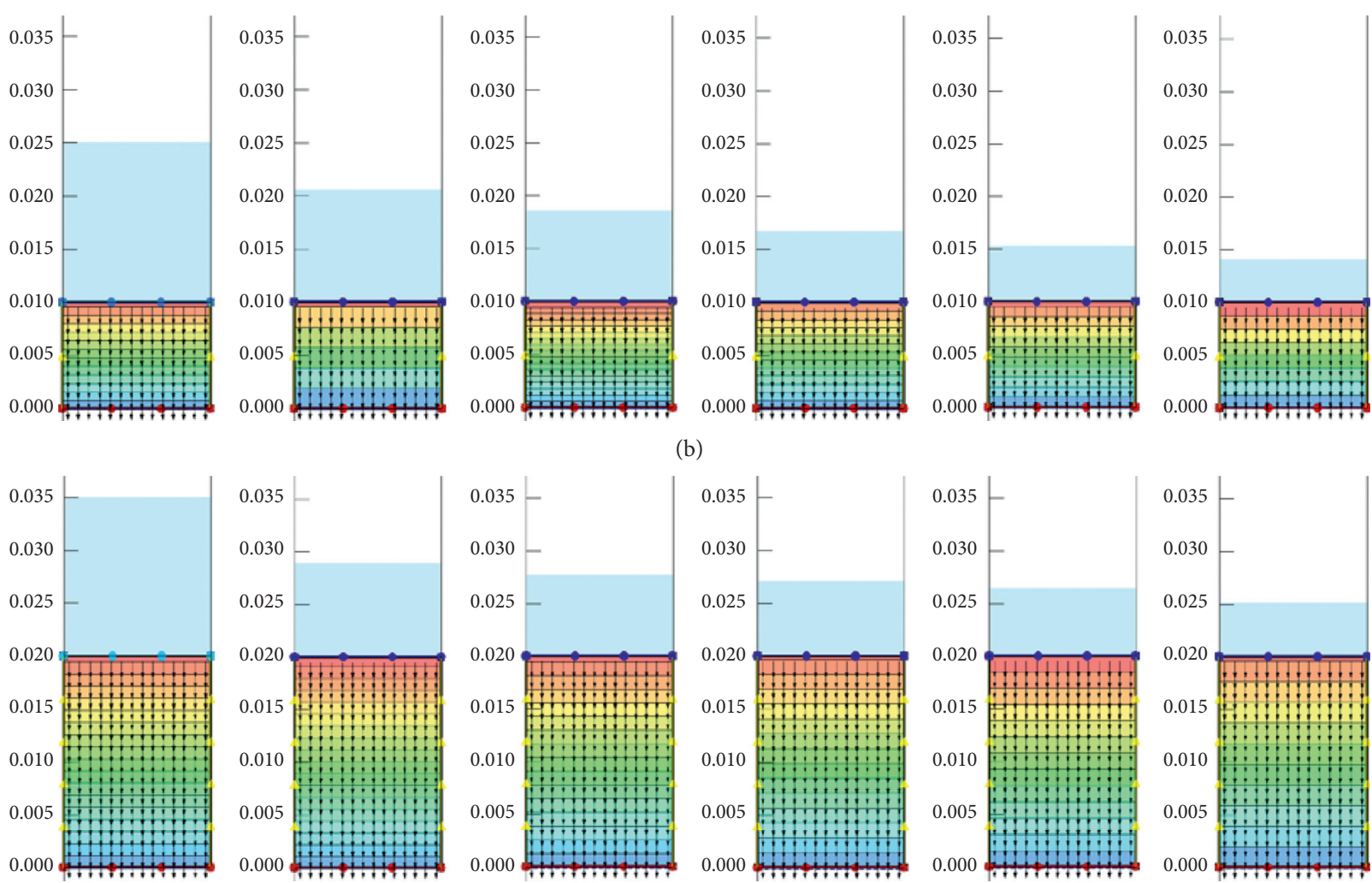

(c)

Figure 12: Numerical simulation total water head stress cloud diagram with different thickness and $0.5 \mathrm{~mm}$ at different times: (a) $0.5 \mathrm{~mm} / 5 \mathrm{~cm}$ soil column pressure head at different times. (b) $0.5 \mathrm{~mm} / 10 \mathrm{~cm}$ soil column pressure head at different times. (c). $5 \mathrm{~mm} / 20 \mathrm{~cm}$ soil column pressure head at different times. 
TABLE 5: Transient head-time-seepage flow relationship.

\begin{tabular}{lccccccccc}
\hline \multirow{2}{*}{ Number } & \multicolumn{3}{c}{ Transient head/cm } & \multicolumn{3}{c}{ Time/h } & \multicolumn{3}{c}{ Seepage flow/m } \\
& $5 \mathrm{~cm}$ & $10 \mathrm{~cm}$ & $20 \mathrm{~cm}$ & $5 \mathrm{~cm}$ & $10 \mathrm{~cm}$ & $20 \mathrm{~cm}$ & $5 \mathrm{~cm}$ & 0 \\
\hline 1 & 15.4 & 13.8 & 10.5 & 0 & 0 & 0 & 0 & 0 \\
2 & 12.1 & 10.7 & 9.0 & 50.6 & 48 & 29.5 & 0.0018 & 0.0021 & 0.0008 \\
3 & 10.5 & 8.5 & 7.7 & 101.3 & 105 & 59.14 & 0.0034 & 0.0042 & 0.0017 \\
4 & 9.4 & 6.7 & 7.1 & 152 & 151 & 88.7 & 0.0048 & 0.0058 & 0.0024 \\
5 & 8.6 & 5.4 & 6.5 & 202.6 & 196 & 108.42 & 0.0061 & 0.0072 & 0.0030 \\
6 & 7.8 & 4.2 & 5.1 & 253.3 & 250 & 138 & 0.0074 & 0.0086 & 0.0037 \\
\hline
\end{tabular}

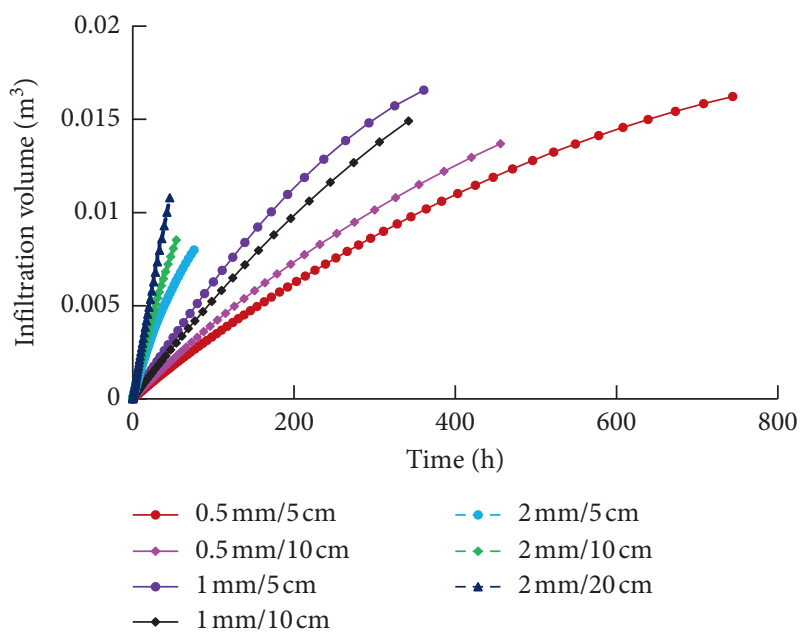

FIgURE 13: Numerical simulation cumulative infiltration volume and time relationship curve.

TABLE 6: Numerical simulation fitting function.

\begin{tabular}{|c|c|c|c|}
\hline \multirow{2}{*}{ Size $/ \mathrm{mm}$} & \multicolumn{3}{|c|}{ Height $/ \mathrm{cm}$} \\
\hline & 5 & 10 & 20 \\
\hline 0.5 & $y=-2 \times 10^{-8} x^{2}+3 \times 10^{-5} x+9 \times 10^{-5}$ & $y=-3 \times 10^{-8} x^{2}+4 \times 10^{-5} x+6 \times 10^{-5}$ & - \\
\hline 1 & $y=-7 \times 10^{-8} x^{2}+7 \times 10^{-5} x-2 \times 10^{-5}$ & $y=-4 \times 10^{-8} x^{2}+6 \times 10^{-5} x+3 \times 10^{-5}$ & - \\
\hline 2 & $y=-7 \times 10^{-7} x^{2}+2 \times 10^{-4} x+6 \times 10^{-5}$ & $y=-8 \times 10^{-7} x^{2}+2 \times 10^{-4} x+6 \times 10^{-5}$ & $y=-4 \times 10^{-7} x^{2}+3 \times 10^{-4} x-5 \times 10^{-7}$ \\
\hline
\end{tabular}

\section{Results and Discussion}

(1) During the period of soil column experiment, there is no visible seepage of water from particle size $0.5 \mathrm{~mm}$ with height $20 \mathrm{~cm}$ and particle size $1 \mathrm{~mm}$ with height $20 \mathrm{~cm}$, which proves that it has good antiseepage performance.

(2) Due to the disintegration characteristics of mudstone in the seepage process, the small particle size mudstone disintegrates quickly, and the particle size is further reduced after disintegration, resulting in a denser soil structure. As the thickness increasing, the soil column does not seep out of water, which is one of the important factors affecting the permeability effect.

(3) For mudstone with a small particle size, since its particle size is small, the degree of disintegration is also small, so the change of its liquid level is fast and then slow to a constant speed until the seepage is complete. After the particle size increases, the degree of disintegration also increases. For the particle size of $2 \mathrm{~mm}$ with a height of $5 \mathrm{~cm}$, the water is completely permeated due to the small height; for the particle size of $2 \mathrm{~mm}$ with a height of $10 \mathrm{~cm}$, the water is not permeated.

(4) In addition to disintegration, water absorption also has a certain impact on the experimental process. Particle size and height are positively correlated with water absorption, so the mudstone of $2 \mathrm{~mm}$ with a height of $20 \mathrm{~cm}$ seeps less water, and most of it is absorbed.

\section{Conclusion}

(1) The particle size is negatively correlated with the infiltration effect, and the influence of mudstone paving thickness on the infiltration effect shows a certain difference. The paving height under the 
condition of particle size of $0.5 \mathrm{~mm}$ and particle size of $2 \mathrm{~mm}$ is negatively related to the average infiltration rate. However, the thickness of $1 \mathrm{~mm}$ particle size has little effect on the antiseepage effect.

(2) The relationship among the average infiltration rate, height, and particle size is obtained by fitting. The average infiltration rate is proportional to the particle size, inversely proportional to the laying height, and inversely proportional to the water barrier effect; the higher the average infiltration rate, the worse the water barrier.

(3) The cumulative infiltration volume is in a quadratic function relationship with time. The infiltration rate gradually decreases with the increase of time and then tends to be linear.

(4) The permeability coefficient calculated by physical experiment is used for numerical simulation, the obtained seepage curve can better restore the process of physical simulation, the results show a quadratic function growth, and the error is within a reasonable range.

\section{Data Availability}

The data used to support the findings of this study are available from the corresponding author upon request.

\section{Conflicts of Interest}

The authors declare that there are no conflicts of interest regarding the publication of this paper.

\section{Acknowledgments}

This study was supported by the National Energy Group 2030 Major Pilot Project (GJNY2030XDXM-19-03.2), Scientific Research Program Funded by Shaanxi Provincial Education Department (18JK0520, 18JS067), the China Postdoctoral Science Foundation (2018M643691, 2016M601913), Shaanxi Innovation Capacity Support Program (2018TD-038), and Young Faculty Innovation Program of Engineering School (XUST, 2017-NY-001). Support from these agencies is gratefully acknowledged.

\section{References}

[1] L. Ma, K. Li, S. Xiao, and X. Ding, "Optimisation study on coordinated mining model of coal reserves buried between adjacent surface mines," International Journal of Oil, Gas and Coal Technology, vol. 1, no. 3, pp. 283-297, 2017.

[2] X. Ma and Q. Fu, "Characteristics analysis and numerical simulation of soil water movement parameters in different freeze-thaw periods," Journal of Applied Basic Science and Engineering, vol. 2, no. 04, pp. 774-787, 2020.

[3] J. Wang, Experimental Study on Layer Reconstruction of OpenPit Coal Mine Dump, China University of Mining and Technology, Xuzhou, China, 2019.

[4] K. ZhaoQ. Xu et al., "Comparative test study on permeability of shallow loess in Heifangtai," Journal of Engineering Geology, vol. 2, no. 2, pp. 459-466, 2018.
[5] S. Li, D. Li, and P. Shi, "Analysis of influencing factors for the determination of permeability coefficient of cohesive soil," Journal of Shandong University of Science and Technology, vol. 3, no. 03, pp. 46-52, 2016.

[6] S. Cao, L. Qiao, Y. Liu, Y. Jiang, and J. Xie, "Error analysis and feasibility study of bentonite permeability test," Chinese Journal of Rock Mechanics and Engineering, vol. 2, no. S2, pp. 4202-4206, 2010.

[7] Y. Chen, W. Ye, Q. Wang, and C. Bao, "Research on influencing factors of permeability of sand-bentonite mixed barrier materials," Journal of Engineering Geology, vol. 1, no. 3, pp. 357-362, 2010.

[8] B. Dolinar, "Predicting the hydraulic conductivity of saturated clays using plasticity-value correlations," Applied Clay Science, vol. 4, no. 1-2, pp. 90-94, 2009.

[9] J. Guo, J. Liu, Q. Li et al., "Variation law of coal permeability under cyclic loading and unloading," Thermal Science, vol. 23, p. $215,2019$.

[10] J. Guo, J. Liu, Q. Li et al., "Experimental study on the failure law of water-bearing coal and the evolution of permeability under plastic flow," Environmental Earth Sciences, vol. 7, no. $14,2020$.

[11] C. A. Burger and C. D. Shackelford, "Evaluating dual porosity of pelletized diatomaceous earth using bimodal soil-water characteristic curve functions," Canadian Geotechnical Journal, vol. 3, no. 1, pp. 53-66, 2001.

[12] W. Niu, W. Ye, C. Bao, and L. Qian, "Soil-water characteristic curve and permeability coefficient of Gaomiaozi bentonite," Chinese Journal of Underground Space and Engineering, no. 5, pp. 952-955, 2009.

[13] R. P. Chapuis, "Predicting the saturated hydraulic conductivity of sand and gravel using effective diameter and void ratio," Canadian Geotechnical Journal, vol. 4, no. 5, pp. 787-795, 2004.

[14] M. Aubertin, R. P. Chapuis, A. Bouchentouf, and B. Bussière, "Unsaturated flow modeling of inclined layers for the analysis of covers," in Proceedings of the 4th International Conference on Acid Rock Drainage, pp. 731-746, Vancouver, Canada, May 1997.

[15] X. Zhu, J. Yan, X. Wang, M. Chen, D. Zhao, and G. Yu, "Laboratory experimental study on the permeability coefficient of silt saturated soil," Water Resources and Hydropower Technology, vol. 4, no. 9, pp. 107-111, 2014.

[16] M. Zhang, M. Jiang, and Y. Zhao, "Nonlinear permeability and parameter determination of dredger fill silt based on GDS consolidation apparatus," Chinese Journal of Rock Mechanics and Engineering, vol. 3, no. 3, pp. 625-632, 2013.

[17] R. P. Chapuis, D. Chenaf, D. Marcotte, and M. Chouteau, "Essai de pompage dans un aquifère à nappe libre à Lachenaie, Québec," in Proceedings of the 51st Canadian Geotechnical Conference, pp. 515-522, Edmonton, Canada, October 1998.

[18] X. Fu and R. Deng, Indoor Rock Mechanics Experiments, Southwest Jiaotong University Press, Chengdu, China, 2014.

[19] C. R. R. Clarkson, Z. Pan, I. Palmer, and S. Harpalani, "Predicting sorption-induced strain and permeability increase with depletion for coalbed-methane reservoirs," SPE Journal, vol. 1, no. 1, pp. 152-159, 2010.

[20] Canada GEO-SLOPE International Co., Ltd., User Guide for Unsaturated Soil Seepage Analysis Software SEEP/W, Metallurgical Industry Press, Beijing, China, 2011.

[21] Y. Wang, B. Shi, L. Gao, and L. Jin, "Experimental study on temperature effect of cohesive soil permeability," Journal of Engineering Geology, vol. 1, no. 3, pp. 351-356, 2010. 
[22] B. Bai and C. Zhao, "Effect of temperature on mechanical properties of cohesive soil," Rock and Soil Mechanics, vol. 24, no. 4, pp. 533-537, 2000.

[23] Z. Gu and B. Sun, "Experimental study on permeability of undisturbed soil, remolded soil and solidified soil," Journal of Rock Mechanics and Engineering, vol. 2, no. 3, pp. 505-508, 2003.

[24] M. Mbonimpa, M. Aubertin, B. Bruno et al., "A model to predict the water retention curve from basic geotechnical properties," Canadian Geotechnical Journal, vol. 4, no. 6, pp. 1104-1122, 2003.

[25] National Bureau of Quality and Technical Supervision, $\mathrm{Na}$ tional Standards of the People's Republic of China, China Planning Press, Beijing, China, 1999.

[26] M. Bi, Y. Qiao, and L. Wang, "Application of Seep/w in the structural optimization of dam foundation wall and curtain combined anti-seepage system," Journal of China Three Gorges University, vol. 3, no. 2, pp. 11-15, 2010.

[27] H. Xiao, Z. Xia, D. Peng et al., "The effect of plant roots on the disintegration performance of purple soil in the water-levelfluctuating zone of the three gorges reservoir," China Soil and Water Conservation Science, vol. 1, no. 3, pp. 98-103, 2019.

[28] B. J. Cosby, G. M. Hornberger, R. B. Clapp et al., "A statistical exploration of the relationships of soil moisture characteristics to the physical properties of soils," Water Resources Research, vol. 2, no. 6, 1984.

[29] L. Ma, X. Lai, J. Zhang, S. Xiao, L. Zhang, and Y. Tu, "Blastcasting mechanism and parameter optimization of a benched deep-hole in an opencast coal mine," Shock and Vibration, vol. 202, no. 4, 11 pages, Article ID 1396483, 2020.

[30] R. P. Chapuis and M. Aubertin, "A simplified method to estimate saturated and unsaturated seepage through dikes under steady-state conditions," Canadian Geotechnical Journal, vol. 3, no. 6, pp. 1321-1328, 2001. 